\title{
Use and Effectiveness of the Cadaver-Lab in Orthopaedic and Traumatology Education: An Italian Survey
}

\author{
Michele Losco ${ }^{1}$ Filippo Familiari ${ }^{2}$ Francesco Giron $^{3}$ Rocco Papalia ${ }^{4}$
}

${ }^{1}$ Department of Orthopaedic and Trauma Surgery, AOUC Azienda Ospedaliero-Universitaria Careggi, Firenze, Italy

Address for correspondence Michele Losco, MD, Department of Orthopaedic and Trauma Surgery, AOU Careggi, Largo Brambilla,

2 Department of Orthopaedic and Trauma Surgery, Università degli 3, Firenze 50134, Italy (e-mail: michelelosco@gmail.com).

Studi “Magna Graecia” di Catanzaro, Campus Universitario

"Salvatore Venuta" Viale Europa, Rome, Italy

${ }^{3}$ Department of Orthopaedic and Trauma Surgery, Ospedale Villa

Salus, Mestre, Italy

${ }^{4}$ Department of Orthopaedic and Trauma Surgery, Policlinico

Universitario Campus Bio-Medico, Rome, Italy

Joints 2017;5:197-201.

\begin{abstract}
Keywords

- orthopaedics

- residents' training

- survey

- cadaver laboratory

Purpose The purpose of this study is to provide basic information on the availability and current use of cadaver laboratories in the education of orthopaedic residents and trainees and to determine the interest for the implementation of this type of training. Methods All Orthopaedic residents and trainees who attended a cadaver laboratory organized by SIGASCOT (Italian Society of the Knee, Arthroscopy, Sports Traumatology, Cartilage and Orthopaedic Technology) between 2013 and 2016 were asked to complete a survey on the availability and current use of cadaver laboratories in the education of Orthopaedic residents and trainees. The survey was sent via e-mail to 102 Orthopaedic residents and trainees. All data were analyzed and all responses are presented as counts, percentages, or means.

Results Thirty-eight (37.2\%) Orthopaedics and traumatology residents and trainees completed the survey and were included in this analysis. Eighteen trainees (18/38; $44.3 \%$ ) attended a cadaver laboratory focused on lower limb surgery, whereas 20 (20/38; 52.7\%) on upper limb surgery. Twenty participants (55.7\%) perceived skills laboratory sessions as extremely beneficial to the understanding and becoming familiar with the normal surgical anatomy; moreover, 16 (45.7\%) participants considered the cadaver laboratory extremely beneficial to the understanding of a specific surgical technique and very beneficial (44.4\%) to become confident with arthroscopic or other specific surgical instruments. Over $60 \%$ of participants perceived cadaver laboratory to be very to extremely beneficial to increase confidence and speed in the operating room $(\mathrm{OR})$, and more than a half of them considered skills laboratory sessions to be extremely beneficial to increase participation and decrease the occurrence of damages in the real surgical activity.

Conclusion Orthopaedic residents and trainees found the addition of a cadaver laboratory for teaching surgical skills a significant benefit to both their overall education and surgical skills training.

Level of Evidence Level IV, survey study.
\end{abstract}

published online December 11, 2017
DOI https://doi.org/ 10.1055/s-0037-1608949. ISSN 2282-4324.
Copyright (c) 2017 Georg Thieme Verlag License terms KG Stuttgart · New York 


\section{Introduction}

Surgical simulation is a well-established technique that has been developed and used for decades to train residents in surgery including, in the last years, Orthopaedic surgery. ${ }^{1,2}$ The classic surgical training that Orthopaedics residents undergo during their residencies includes exposure to procedures, the use of data and log books to quantify their surgical experience, and personal feedback from senior colleagues. This classic approach is often very subjective, not always valid, and subject to errors if we compare it to relatively new approaches that include cadaver laboratories, animal/synthetic models, and more recently virtual reality. Residents in Orthopaedic surgery should be trained and evaluated with more objective tools on standard surgical procedures to allow their progression toward a high level of competence that needs to be quantified. Quality remains the main focus of Orthopaedic residents' training with mutual benefit for both residents and patients. ${ }^{2}$

Surgical simulation can be divided into cadaver laboratories, animal/synthetic models, and virtual reality. ${ }^{3}$ Synthetic specimens are currently used for the training of future surgeons with the advantage of being highly standardized. ${ }^{4,5}$ Animal models are realistic and generally low cost, while virtual reality and computer-based simulations are highly uniformed with low running costs, but not available for all surgical procedures at the moment. ${ }^{6}$

Cadaver sessions are an essential part of surgical training and reputed to be the best available substitute for live surgery nowadays. Arthroscopy and arthroplasty are commonly performed on cadavers allowing and facilitating experience on surgical exposures and procedures. It allows the trainee to have direct and real feedback while developing anatomical awareness of different structures and their manipulation. Moreover, the major part of complex procedures including joint replacements cannot be adequately reproduced by means of other techniques including virtual simulation that is not available as yet for certain surgical procedures such as pedicle screw placement in spine surgery. ${ }^{7}$ There are also few limitations to the use of cadaver laboratories including specimen availability and storing and management costs of the training facilities. For this reason, despite cadaver laboratories are considered the gold standard $^{7}$ on other forms of simulation in Orthopaedic surgery training, it is pivotal to evaluate the circumstances in which cadaver training will provide the highest benefit to the trainee considering the resources available.

The purpose of this study is to provide basic information on the availability and current use of cadaver laboratories in the education of Orthopaedic residents and trainees and to determine the interest for the implementation of this type of training.

\section{Methods}

All orthopaedic residents and trainees who attended a cadaver laboratory organized by SIGASCOT (Italian Society of the Knee, Arthroscopy, Sports Traumatology, Cartilage and Orthopaedic Technology) between 2013 and 2016 were asked to complete a survey on the availability and current use of cadaver laboratories in the education of Orthopaedic residents and trainees.

An online questionnaire was built using SurveyMonkey (Portland, Oregon, United Sates), a free, open source software survey tool on the web. The survey was sent via e-mail to 102 Orthopaedic residents and trainees on April 12, 2017. All the invitees received an e-mail shortly afterward containing a brief explanation of the purpose of the survey and were asked to click on a link that would lead them to the appropriate version of the survey. The survey required $\sim 5$ to 8 minutes to complete. The survey needed to be brief to maximize the response rate. The survey was closed on April 25, 2017. The questions and responses applicable to this part of the study are included in -Table 1.

We collected results electronically and anonymously. All data were analyzed using Microsoft Excel. All responses are presented as counts, percentages, or means.

\section{Results}

Thirty-eight out of 102 Orthopaedics and traumatology residents and trainees (37.2\%) completed the survey and were included in this analysis. The demographic data and postgraduate levels of the participants included in the study are summarized in -Table 2. The resources that participants mostly use for their orthopaedics and traumatology education are based on scientific journals (59.5\%), conferences (45.9\%), cadaver laboratories and Internet-based learning (35.1\%), textbooks (24.3\%), and bone model courses (5.45\%) (-Fig. 1).

The totality of the trainees already attended at least one cadaver laboratory before the one included in this study and most of them (45.9\%) attended more than five sessions. Eighteen trainees $(18 / 38 ; 44.3 \%)$ attended a cadaver laboratory focused on lower limb surgery (knee or foot and ankle or hip), whereas $20(20 / 38 ; 52.7 \%)$ on upper limb surgery (shoulder or elbow or wrist).

- Table 3 summarizes the perception of benefits that trainees had in regards to skills laboratory sessions attended. Twenty participants (55.7\%) perceived skills laboratory sessions as extremely beneficial to the understanding and becoming familiar with the normal surgical anatomy; moreover, 16 (45.7\%) participants considered the cadaver laboratory extremely beneficial to the understanding of a specific surgical technique (both arthroscopic and open surgery) and very beneficial (44.4\%) to become confident with arthroscopic or other specific surgical instruments. Practicing on the cadaveric specimens was perceived as very to extremely beneficial in $80.6 \%$ of cases (29/36) overall.

Skills laboratory sessions were perceived by the majority of respondents as being beneficial to the operating room (OR) experience (-Table 4 ). Over $60 \%$ of participants perceived cadaver laboratory to be very to extremely beneficial to increase confidence and speed in the OR and more than a half of them considered skills laboratory sessions to be very to extremely beneficial to increase participation and decrease the occurrence of damages in the real surgical activity ( - Table 4). No significant differences in trainees' responses were noticed in regards to the year in training. 
Table 1 Questions asked and possible responses

\begin{tabular}{|c|c|c|}
\hline & Questions & Possible responses \\
\hline \multirow[t]{7}{*}{1.} & \multirow[t]{7}{*}{ In which year of residency are you right now? } & PGY1 \\
\hline & & PGY2 \\
\hline & & PGY3 \\
\hline & & PGY4 \\
\hline & & PGY5 \\
\hline & & Already graduated from residency \\
\hline & & Please specify your age: \\
\hline \multirow[t]{6}{*}{2.} & \multirow{6}{*}{$\begin{array}{l}\text { What kind of resources do you mostly use in your Orthopaedic education? } \\
\text { (maximum two choices) }\end{array}$} & Journals \\
\hline & & Textbooks \\
\hline & & Interned-based learning \\
\hline & & Courses (bone models) \\
\hline & & Cadaver labs \\
\hline & & Other (please specify) \\
\hline \multirow[t]{7}{*}{3.} & \multirow[t]{7}{*}{ How many cadaver laboratories did you attended in your life? } & 0 \\
\hline & & 1 \\
\hline & & 2 \\
\hline & & 3 \\
\hline & & 4 \\
\hline & & 5 \\
\hline & & $>5$ \\
\hline \multirow[t]{2}{*}{4.} & \multirow[t]{2}{*}{ Which anatomical district was the cadaver laboratory focusing on? } & Upper limb (please specify joint) \\
\hline & & Lower limb (please specify joint) \\
\hline \multirow[t]{4}{*}{5.} & \multirow[t]{4}{*}{ How beneficial did you find practicing on the cadaveric specimen? } & Not beneficial at all \\
\hline & & Slightly beneficial \\
\hline & & Very beneficial \\
\hline & & Extremely beneficial \\
\hline \multirow[t]{4}{*}{6.} & \multirow{4}{*}{$\begin{array}{l}\text { How beneficial did you find practicing on the cadaveric specimen to become } \\
\text { familiar with basic arthroscopic instruments or specific surgical } \\
\text { instruments? }\end{array}$} & Not beneficial at all \\
\hline & & Slightly beneficial \\
\hline & & Very beneficial \\
\hline & & Extremely beneficial \\
\hline \multirow[t]{4}{*}{7.} & \multirow{4}{*}{$\begin{array}{l}\text { How beneficial did you find practicing on the cadaveric specimen to } \\
\text { understand a specific surgical technique? }\end{array}$} & Not beneficial at all \\
\hline & & Slightly beneficial \\
\hline & & Very beneficial \\
\hline & & Extremely beneficial \\
\hline \multirow[t]{4}{*}{8.} & \multirow{4}{*}{$\begin{array}{l}\text { How beneficial did you find practicing on the cadaveric specimen to become } \\
\text { familiar with normal surgical anatomy? }\end{array}$} & Not beneficial at all \\
\hline & & Slightly beneficial \\
\hline & & Very beneficial \\
\hline & & Extremely beneficial \\
\hline \multirow[t]{4}{*}{9.} & \multirow{4}{*}{$\begin{array}{l}\text { Did cadaver laboratories increase your confidence, rapidity, and efficiency } \\
\text { during OR cases? }\end{array}$} & Not beneficial at all \\
\hline & & Slightly beneficial \\
\hline & & Very beneficial \\
\hline & & Extremely beneficial \\
\hline \multirow[t]{4}{*}{10.} & \multirow{4}{*}{$\begin{array}{l}\text { Did cadaver laboratories increase your ability to participate more actively to } \\
\text { OR cases and did they decrease the incidence of damage to normal } \\
\text { structures during OR cases? }\end{array}$} & Not beneficial at all \\
\hline & & Slightly beneficial \\
\hline & & Very beneficial \\
\hline & & Extremely beneficial \\
\hline
\end{tabular}

Abbreviations: OR, operating room; PGY, postgraduate year. 
Table 2 Gender and year in training of respondents

\begin{tabular}{|l|l|}
\hline & Frequency (\%) \\
\hline Gender & $N=38$ \\
\hline Male & $33(86.8)$ \\
\hline Female & $5(13.2)$ \\
\hline Year in training & $N=38$ \\
\hline PGY1 & $0(0)$ \\
\hline PGY2 & $0(0)$ \\
\hline PGY3 & $0(0)$ \\
\hline PGY4 & $2(5.2)$ \\
\hline PGY5 & $5(13.2)$ \\
\hline AGFR & $31(81.6)$ \\
\hline
\end{tabular}

Abbreviations: AGFR, already graduated from residency; PGY, postgraduate year.

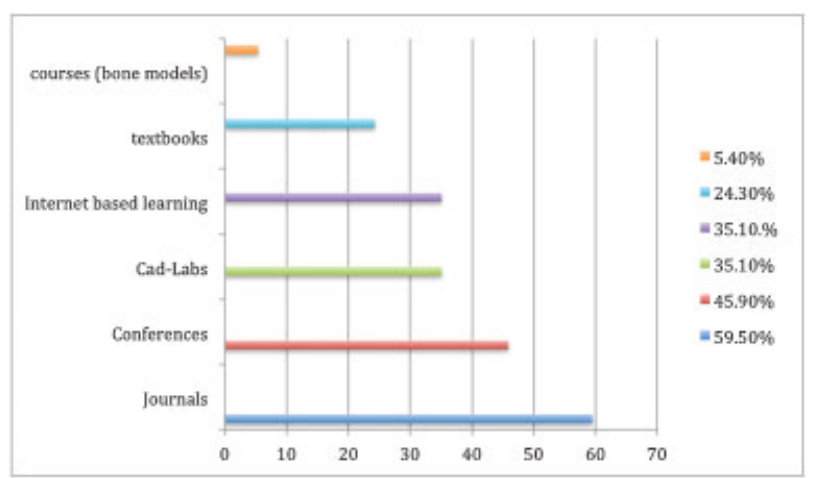

Fig. 1 Mostly used educational resources.

\section{Discussion}

This study was performed in collaboration with SIGASCOT. Aiming to identify the challenges that Orthopaedics and traumatology residents and junior Orthopaedics and traumatology surgeons face in Italy, as regards to their training, this survey stands as a pioneering study with a consistent participation rate.

There is mounting evidence that the learning curve for both Orthopaedics residents and trainees can be safely advanced outside of the OR by existing simulation technology, with the possibility of an associated decrease in intraoperative technical errors and thus a reduction in patient morbidity. ${ }^{2}$ Many studies demonstrate the constructiveness and validate the simulations. ${ }^{4,6,8}$ For instance, in Orthopaedic surgery, studies involving cadaver-based simulations of carpal tunnel surgery have shown the possibility to distinguish between the performances of residents with different experience levels. ${ }^{9}$ Residents subjectively valued the cadaver laboratory sessions as an additional and better tool with respect to other resources in acquiring specific surgical skills. ${ }^{10}$ The survey demonstrated the cadaver laboratory sessions was a well-known instrument for residents and trainees as demonstrated by all of them having attended at least one previous cadaver session with a high percentage of trainees (45.9\%) having been involved in more than five.

The persons enrolled in our study perceived the cadaver session to be of value for learning and practicing the basics of arthroscopy, revising surgical anatomy, and they considered the skills practiced in the laboratory to be transferable to the OR through increased confidence, speed, and efficiency and participation. If it is true that laboratory practicing translates

Table 3 Perceived benefits of skills laboratory sessions

\begin{tabular}{|l|l|l|l|l|}
\hline & $\begin{array}{l}\text { Not } \\
\text { beneficial } \\
N(\%)\end{array}$ & $\begin{array}{l}\text { Slightly } \\
\text { beneficial } \\
N(\%)\end{array}$ & $\begin{array}{l}\text { Very } \\
\text { beneficial } \\
N(\%)\end{array}$ & $\begin{array}{l}\text { Extremely } \\
\text { beneficial } \\
N(\%)\end{array}$ \\
\hline Practicing on the cadaveric specimen & $0(0)$ & $7(19.4)$ & $14(38.9)$ & $15(41.7)$ \\
\hline $\begin{array}{l}\text { Familiarity with basic arthroscopic instruments } \\
\text { or specific surgical instruments }\end{array}$ & $0(0)$ & $7(19.4)$ & $16(44.4)$ & $13(36.1)$ \\
\hline To understand a specific surgical technique & $0(0)$ & $6(17.1)$ & $13(37.1)$ & $16(45.7)$ \\
\hline Familiarity with normal surgical anatomy & $0(0)$ & $5(13.9)$ & $11(30.6)$ & $20(55.7)$ \\
\hline
\end{tabular}

Note: (1), (2), (4), $N=36 ;$ (3), $N=35$.

Table 4 Perceived benefits of skills laboratory sessions to the OR experience

\begin{tabular}{|l|l|l|l|l|}
\hline & $\begin{array}{l}\text { Not } \\
\text { beneficial } \\
N(\%)\end{array}$ & $\begin{array}{l}\text { Slightly } \\
\text { beneficial } \\
N(\%)\end{array}$ & $\begin{array}{l}\text { Very } \\
\text { beneficial } \\
N(\%)\end{array}$ & $\begin{array}{l}\text { Extremely } \\
\text { beneficial } \\
N(\%)\end{array}$ \\
\hline Confidence, speed, and rapidity in OR & $1(2.9)$ & $12(34.3)$ & $15(42.9)$ & $7(20)$ \\
\hline $\begin{array}{l}\text { Participation and decrease of } \\
\text { incidence of damage in OR }\end{array}$ & $1(2.8)$ & $14(38.9)$ & $14(38.9)$ & $7(19.4)$ \\
\hline
\end{tabular}

Abbreviation: OR, operating room.

Note: (1), $N=35 ;(2), N=36$. 
to more efficient performance in the OR, then patients also stand to benefit through decreased anesthesia and OR time and likely through decreased risk of iatrogenic injury.

The opportunity for repetitive practice in arthroscopic skills over the course of an Orthopaedic residency is appealing, as it has been shown that procedural skills are not retained without repetitive exposure, suggesting that repetition and multiple training episodes are preferable. ${ }^{8}$ Previous surveys developed by medical schools and teaching faculties involved in training programs also suggest numerous exposures are needed for trainees to gain proficiency in common Orthopaedic arthroscopic procedures. ${ }^{11}$ A significant learning curve exists with exposure to new arthroscopic procedures, even for practicing surgeons, suggesting that repetitive practice is essential for residents where all aspects of arthroscopy are new. ${ }^{12}$ A skill laboratory is a way to enable residents to practice surgical skills without the time constraints associated with the OR.

The skills-based resident training programs, which have recently become an upcoming trend throughout the world, aims at increasing residents' surgical technique and skill by means of the use of plastic models, simulators, and cadavers. Such laboratories are believed to increase the familiarity of the residents with surgical equipment, procedures, and techniques at low risk and costs. ${ }^{11}$

There is literature to suggest that simulation training can be transferred to increase competency and skills in the OR. In a 2008 study on the effect of laboratory-based simulation on resident ability to perform knee diagnostic arthroscopy, Howells et al demonstrated improved skills in trainees that underwent repetitive instruction using a bench-top knee simulator. ${ }^{8}$ Vitale et al surveyed more than 2,400 members of the American Academy of Orthopaedic Surgeons and found that practice on cadaveric specimens ranked third in importance in regards to learning arthroscopic rotator cuff repair technique. ${ }^{13}$ In addition, skills assessment systems are being developed for use in simulated learning situations. ${ }^{14}$ Our survey results showed that the skills laboratory was highly appreciated by our trainees in learning both open and arthroscopic techniques. Substantial benefit was noted in becoming confident with equipment, instruments, procedures, anatomy, and especially with practicing the three-dimensional aspect of arthroscopy. Our residents felt that skills laboratory sessions resulted in increased confidence, efficiency, and participation in the OR.

The low response rate is a limitation of this study, although higher compared with other published studies. Only 38 (37.2\%) of the 102 orthopaedic residents and trainees invited to participate to the survey responded. However, a survey of both Orthopaedic program directors and residents regarding arthroscopic training in the United States' residency programs had response rates of 15.9 and $11.1 \%$, respectively. ${ }^{15}$ Another study in which Orthopaedic program directors and residents were surveyed regarding their attitude toward resident work hours had response rates of 56 and $30 \%$, respectively. ${ }^{16}$ Moreover, our sample size was small and the data available from our study are limited and not fully manageable in terms of detailed statistical analysis. Small sample size may limit the accuracy required to detect differences between different postgraduate year levels.

In conclusion, Orthopaedic residents and trainees have found the addition of a cadaver laboratory for teaching surgical skills to be of significant benefit to both their overall education and surgical skills training.

\section{Conflict of Interest}

None.

\section{References}

1 Sanfey HA, Dunnington GL. Basic surgical skills testing for junior residents: current views of general surgery program directors. J Am Coll Surg 2011;212(03):406-412

2 Karam MD, Pedowitz RA, Natividad H, Murray J, Marsh JL. Current and future use of surgical skills training laboratories in orthopaedic resident education: a national survey. J Bone Joint Surg Am 2013;95(01):e4

3 Atesok K, Mabrey JD, Jazrawi LM, Egol KA. Surgical simulation in orthopaedic skills training. J Am Acad Orthop Surg 2012;20(07): 410-422

4 Leong JJ, Leff DR, Das A, et al. Validation of orthopaedic bench models for trauma surgery. J Bone Joint Surg Br 2008;90(07): 958-965

5 Elfar J, Menorca RM, Reed JD, Stanbury S. Composite bone models in orthopaedic surgery research and education. J Am Acad Orthop Surg 2014;22(02):111-120

6 Henn RF III, Shah N, Warner JJ, Gomoll AH. Shoulder arthroscopy simulator training improves shoulder arthroscopy performance in a cadaveric model. Arthroscopy 2013;29(06):982-985

7 Akhtar KS, Chen A, Standfield NJ, Gupte CM. The role of simulation in developing surgical skills. Curr Rev Musculoskelet Med 2014;7 (02):155-160

8 Howells NR, Gill HS, Carr AJ, Price AJ, Rees JL. Transferring simulated arthroscopic skills to the operating theatre: a randomised blinded study. J Bone Joint Surg Br 2008;90(04):494-499

9 Van Heest A, Putnam M, Agel J, Shanedling J, McPherson S, Schmitz C. Assessment of technical skills of orthopaedic surgery residents performing open carpal tunnel release surgery. J Bone Joint Surg Am 2009;91(12):2811-2817

10 Wolf BR, Britton CL. How orthopaedic residents perceive educational resources. Iowa Orthop J 2013;33:185-190

11 O'Neill PJ, Cosgarea AJ, Freedman JA, Queale WS, McFarland EG. Arthroscopic proficiency: a survey of orthopaedic sports medicine fellowship directors and orthopaedic surgery department chairs. Arthroscopy 2002;18(07):795-800

12 Snow M, Stanish WD. Double-bundle ACL reconstruction: how big is the learning curve? Knee Surg Sports Traumatol Arthrosc 2010; 18(09):1195-1200

13 Vitale MA, Kleweno CP, Jacir AM, Levine WN, Bigliani LU, Ahmad CS. Training resources in arthroscopic rotator cuff repair. J Bone Joint Surg Am 2007;89(06):1393-1398

14 Insel A, Carofino B, Leger R, Arciero R, Mazzocca AD. The development of an objective model to assess arthroscopic performance. J Bone Joint Surg Am 2009;91(09):2287-2295

15 Hall MP, Kaplan KM, Gorczynski CT, Zuckerman JD, Rosen JE. Assessment of arthroscopic training in U.S. orthopedic surgery residency programs-a resident self-assessment. Bull NYU Hosp Jt Dis 2010;68(01):5-10

16 Immerman I, Kubiak EN, Zuckerman JD. Resident work-hour rules: a survey of residents' and program directors' opinions and attitudes. Am J Orthop 2007;36(12):E172-E179 